\title{
Clinical effects of sinus surgery and adjuvant therapy in cystic fibrosis patients - can chronic lung infections be postponed? *
}

\author{
Kasper Aanaes ${ }^{1}$, Helle Krogh Johansen², Marianne Skov ${ }^{3,4}$, \\ Frederik F. Buchvald ${ }^{3,4}$, Thomas Hjuler ${ }^{1}$, Tacjana Pressler ${ }^{3,4}$, \\ Niels Høiby 2,5, Kim G. Nielsen ${ }^{3,4}$ Christian von Buchwald'
}

Rhinology 51: 222-230, 2013

DOI:10.4193/Rhino12.207

*Received for publication: December 9, 2012

Accepted: March 27, 2013

' Department of Otorhinolaryngology, Head \& Neck Surgery and Audiology, Rigshospitalet and Faculty of Health and Medical Sciences, University of Copenhagen, Denmark

2 Department of Clinical Microbiology 9301, Rigshospitalet, Copenhagen, Denmark

${ }^{3}$ Danish PCD \& chILD Centre, CF Centre Copenhagen, Paediatric Pulmonary Service, Department of Paediatrics and Adolescent

Medicine, Copenhagen University Hospital, Rigshospitalet, Copenhagen, Denmark

${ }^{4}$ Copenhagen CF Centre, Rigshospitalet, Copenhagen, Denmark

${ }^{5}$ Department of International Health, Immunology and Microbiology, The Faculty of Health Sciences, Panum Institute, The University

of Copenhagen, Copenhagen, Denmark

\section{Summary}

Background: The paranasal sinuses can be a bacterial reservoir for pulmonary infections in patients with cystic fibrosis (CF)

Methodology: In this prospective, non-randomised, uncontrolled, intervention cohort study, the clinical effect of sinus surgery followed by two weeks' intravenous antibiotics, 6 months' antibiotic nasal irrigations was assessed in 106 CF patients.

Results: One year after sinus surgery, the prevalence of intermittently colonised patients had decreased by $38 \%$, while the prevalence of non-colonised patients had increased by $150 \%$. The frequency of pulmonary samples with CF pathogens was reduced after surgery. Specific lgG against $P$. aeruginosa decreased after six months. Additionally, the self reported symptoms of chronic rhinosinusitis and quality of life improved.

Conclusion: Combined sinus surgery and postoperative systemic and topical antibiotic treatment significantly reduced the frequency of pulmonary samples positive for CF pathogens in the first year after sinus surgery.

Key words: cystic fibrosis, paranasal sinus surgery, lower airway cultures, Pseudomonas aeruginosa, quality of life, pulmonary function

\section{Introduction}

A marked association exists between upper and lower airway cultures in patients with cystic fibrosis (CF) ${ }^{(1-3)}$ due to the paranasal sinuses often being colonised by CF-lung-pathogenic Gram-negative bacteria ${ }^{(2,3)}$. The environment in the sinuses and the lower airways is similar ${ }^{(1,4,5)}$, albeit the sinus colonisations are dominated by the non-inflammatory IgA antibodies and lack of polymorphonuclear leukocytes ${ }^{(3,6)}$. The sinuses can therefore be an evolutionary 'nest' in early airway colonisations, where the bacteria diversify, evolving antibiotic resistance and other phenotypes associated with adaptation to the CF airways in general. Subsequently the bacteria migrate and intermittently colonise 
the lungs and may ultimately cause chronic lung infections ${ }^{(2-4,7)}$. Likewise, the sinuses in lung transplanted (LTX) CF patients are regarded as a bacterial reservoir, causing lung allograft infections and rejections ${ }^{(8)}$.

CF pathogens can potentially be eradicated with functional endoscopic sinus surgery (FESS) and postoperative antibiotic treatment ${ }^{(9,10)}$. It has been hypothesized that FESS can reduce the frequency of lung colonisations and may postpone chronic lung infections ${ }^{(2,3)}$. Nevertheless, large-scale prospective studies on the effects of FESS on lung colonisation and infection in CF are lacking ${ }^{(1)}$, and data on surgical therapy for CF patients with chronic rhinosinusitis (CRS) are primarily level III evidence ${ }^{(1,11)}$. Thus, the aim of this prospective cohort study was to assess various clinical effects of FESS followed by topical steroids and intravenous and nasal antibiotics.

\section{Materials and methods}

Study population

Patients were recruited among the $300 \mathrm{CF}$ patients treated at the CF Centre in Copenhagen. The diagnosis of CF was based on clinical characteristics, abnormal sweat electrolytes, and genotype. CF patients followed a routine protocol with monthly medical examinations including lung function tests and lower airway samples taken for microbiological culture (coughed sputum, induced sputum or endolaryngeal suction). Additional lower airway samples were taken whenever patients were hospitalised or when clinical and/or paraclinical parameters indicated a risk of lung colonisation or infection. Approximately every third month, blood samples were taken for analyses including specific antibodies against relevant Gram-negative bacteria (12). LTX patients followed a different outpatient setting with fewer routine samples taken.

All CF pathogens were treated with antibiotics regardless of clinical symptoms according to the Copenhagen CF centre's treatment protocols ${ }^{(13)}$.

\section{Grading of pulmonary infection}

Modified Leeds criteria ${ }^{(14)}$ were employed:

1. Non-infected: no growth of CF pathogens (Pseudomonas aeruginosa, Achromobacter xylosoxidans or Burkholderia cepacia complex) over 12 months (CF-).

2. Intermittently colonised: growth in $>0 \%$ but $\leq 50 \%$ of samples over 12 months (CF+(i)).

3. Chronically infected: growth in $>50 \%$ of a patient's monthly lower airway samples over 12 months (CF+(c)).

\section{Design}

A prospective, non-randomized, uncontrolled, intervention study was conducted over 31/2 years including CF patients aged more than six years with FESS from July 2007 to January 2011. Those included had approximately one year of follow-up with postoperative treatment, lower airway samples cultured, spirometry, body weight, serum samples, and questionnaires (Figure 1). These data were compared with preoperative data from the same patients extracted from our CF database.

In patients who had FESS more than once within the period of the study, only the pre- and postoperative data of the primary FESS was included in the calculations. In four patients, no CF pathogens were found in the lungs at any time the year prior to the primary FESS; in contrast, CF pathogens were found in the lungs the year prior to the secondary FESS. In these four patients, only the pre- and postoperative data referring to the secondary FESS was evaluated, as the main outcome of this study was to evaluate whether FESS could reduce CF-lung-pathogenic Gram-negative bacteria.

During the study period, the protocol was supplemented by additional clinical outcome measures: the sinonasal outcome test (SNOT-22) was included from May 2009, the Cystic Fibrosis Questionnaire-Revised (CFQ-R) questionnaire from November 2009, and bronchoalveolar lavage (BAL) during FESS from December 2009.

\section{Inclusion criteria}

The patients were selected for FESS based on the following criteria:

1. Search for an infectious focus: $(C F+(i))$ patients with increasing frequency of positive lower airway cultures or repeatedly declining lung function (> 10\%), despite inten-

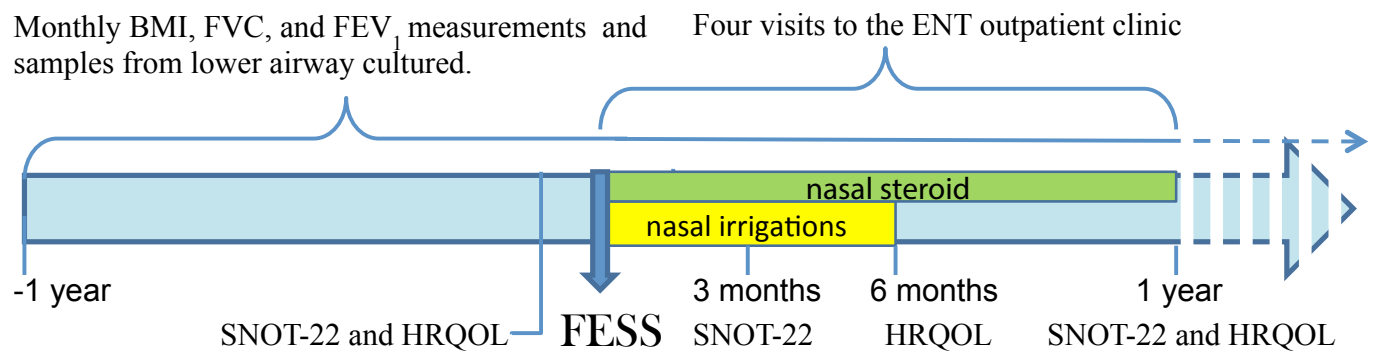

Figure 1. Time-line showing the interventions in the study. 
sive antibiotic chemotherapy. Patients with an unknown infectious focus and increasing antibodies against $P$. aeruginosa, A. xylosoxidans or B. cepacia complex were given the highest priority.

2. Patients who had recently been LTX.

3. Patients with severe symptoms of chronic rhinosinusitis (CRS) according to the European Position Paper on Rhinosinusitis ${ }^{(1)}$, when conservative treatment was unsuccessful.

\section{Perioperative BAL and functional endoscopic sinus surgery} (FESS)

A BAL was performed under general anaesthetic. The subsequent FESS was to ventilate and drain the paranasal sinuses and to make these accessible for postoperative instrumental cleansing and irrigation with saline and topical antibiotics. Each patient was evaluated for symptoms of chronic rhinosinusitis (1) followed by a clinical examination. The extension of surgery (e.g., exploration of the frontal or sphenoid sinuses) was undertaken based on the mandatory preoperative CT scan and perioperative findings. As a standard, we applied FESS with an uncinectomy, an anterior ethmoidectomy and a medial antrostomy, leaving a significantly enlarged maxillary ostium comprising more than half the medial maxillary wall as recommended ${ }^{(1)}$. Visible intramucosal abscess-like structures (especially found in the maxillary sinuses) were resected along with other inflamed mucosal tissue when accessible. Following the surgical procedure, the opened and now accessible sinuses were irrigated with saline and colistimethate sodium.

\section{Bacteriology}

To optimise sinus culture results, multiple perioperative samples were obtained including nasal secretions, pus, mucosal tissue, polyps, and bone. All patients had samples were collected with sharp instruments and by suction. Sinus and lower airway samples were cultured aerobically and anaerobically at $37^{\circ} \mathrm{C}$ on standard agar media for 5-7 days as previously described ${ }^{(15)}$.

\section{Postoperative treatment}

Postoperative adjuvant therapy included: two weeks of IV antibiotics ${ }^{(13)}$, at least 6 months of twice daily nasal irrigation with saline and antibiotics (starting Day 1 with colistimethate sodium but could be adjusted according to susceptibility), and 12 months of topical nasal steroids (mometasonfuroate). As a standard each patient had four postoperative visits to the ENT outpatient clinic where crusts and secretions were endoscopically cleansed (Figure 1). Due to lack of preceding research, the duration of the medical treatment was only determined by the time of outpatient visits where the treatment could be discussed.

\section{Lower airway cultures}

The percentage of the lower airway samples taken monthly and positive for CF pathogens (P. aeruginosa, A. xylosoxidans or $B$. cepacia complex) 365-0 days before FESS was compared with cultures taken 1-365 days after FESS. Additionally, the grade of pulmonary infection (CF-, $\mathrm{CF}+(\mathrm{i}), \mathrm{CF}+(\mathrm{c})$ ) at surgery was compared with the grade one year postoperatively ${ }^{(14)}$. In patients who underwent LTX within the year before FESS, only the days after the LTX were evaluated. If more than one CF pathogen was cultured, only the most frequently cultured bacterium was evaluated. We did not differentiate between how the lower airway samples were obtained (expectoration, endolaryngeal suction or BAL).

\section{Spirometry}

Spirometry was performed at every clinical visit. The average of all measurements expressed as percent of predicted values $(16,17)$ and trend slopes of FVC and FEV1 were calculated 6 and 12 months pre-and postoperatively in 104 patients (two LTX patients had no postoperative values).

\section{Body mass index}

Body mass index standard deviation scores (BMI z-scores) ${ }^{(18)}$ were calculated at every clinical visit. The average percentages and z-BMI trend slopes were calculated 6 and 12 months preand postoperatively.

\section{Serum antibodies}

Elevated levels of specific anti-Pseudomonas lgG antibodies measured by ELISA is a risk factor for developing chronic $P$. aeruginosa infection ${ }^{(19)}$. Averages of anti-Pseudomonas IgG values measured 6 and 12 months pre-and postoperatively were compared in patients with no chronic infection.

\section{SNOT-22}

The SNOT-22 questionnaire focuses on sinonasal conditions (20). It contains 22 items graded from 0 (no problem) to 5 (problem as bad as it can be). Some items are specific while others are more general, for example cough and fatigue. We initiated a back and forth translation from English to Danish according to accepted international criteria.

\section{Health-related qualify of life (HRQOL)}

The Cystic Fibrosis Questionnaire-Revised (CFQ-R) measures disease-specific HRQOL ${ }^{(21)}$. The questionnaires and domains can be viewed at: http://www.psy.miami.edu/cfq_QLab. Two questionnaires were used: one for patients aged more than 13 years (maximum score of 201), and one for those aged 6-13 years (maximum score of 177). As we were interested in the changes over time and not the actual score, the scores of the two questionnaires were analysed together.

\section{Ethics}

In consultation with the local ethics committee, it was deter- 
Table 1. Demographic data on the included 106 CF patients divided by their grade of pulmonary infection.

\begin{tabular}{lcccc} 
& $\begin{array}{c}\text { Non- } \\
\text { infected }\end{array}$ & $\begin{array}{c}\text { Intermit- } \\
\text { tently } \\
\text { colonized }\end{array}$ & $\begin{array}{c}\text { Chronically } \\
\text { infected }\end{array}$ & Total \\
\hline $\begin{array}{l}\text { Male/female } \\
\text { 8/8 }\end{array}$ & $29 / 32$ & $12 / 17$ & $49 / 57$ \\
$\begin{array}{l}\text { Median age in } \\
\text { years at FESS } \\
\text { (range) }\end{array}$ & $18(6-44)$ & $15(6-50)$ & $30(11-46)$ & $19(6-50)$ \\
$\begin{array}{l}\text { F508del } \\
\text { homozygous / } \\
\text { heterozygous/ } \\
\text { other muta- } \\
\text { tions }\end{array}$ & $13 / 3 / 0$ & $41 / 16 / 4$ & $17 / 12 / 0$ & $71 / 31 / 4$ \\
\hline
\end{tabular}

Table 2. The distribution of 106 CF patients in different groups according to grading of pulmonary infection at FESS and the year after FESS; a significant increase of (CF-) patients and a decrease of (CF+(i)) is observed.

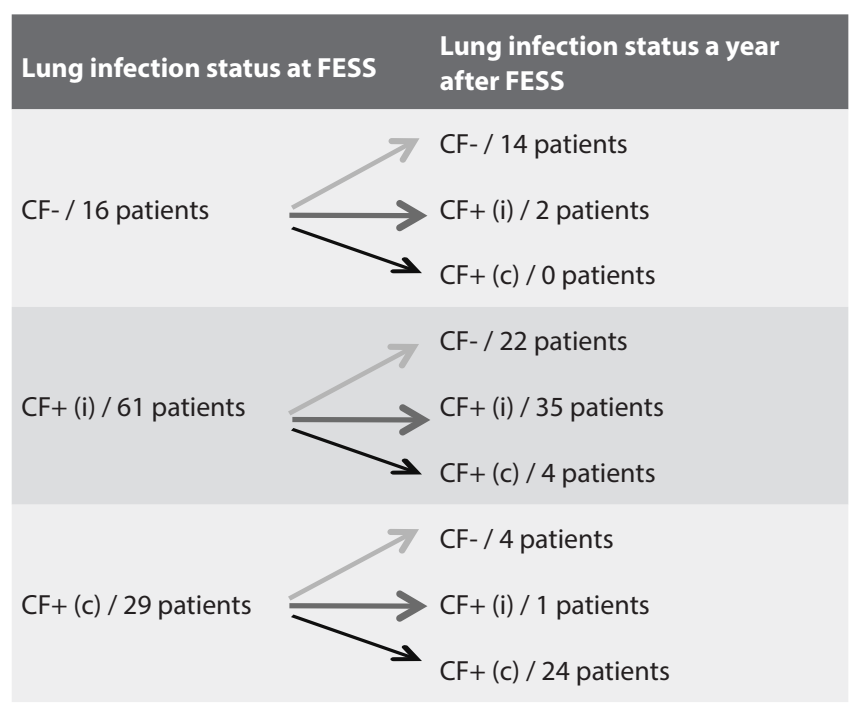

CF-: non-colonised; CF+(i): intermittently colonised; CF+(c): chronically infected.

Table 3. An overview of four chronically infected CF patients showing a long postoperative period without re-growth of $P$. aeruginosa (PA) or A. xylosoxidans $(\mathrm{AX})$ in the lower airway samples.

\begin{tabular}{|c|c|c|c|c|c|c|c|}
\hline CF patient & $\begin{array}{l}\text { Lung } \\
\text { bacteriology }\end{array}$ & $\begin{array}{c}\text { Sinus } \\
\text { bacteriology }\end{array}$ & $\begin{array}{l}\text { Precipitating } \\
\text { antibodies } \\
\text { against PA or } \\
\text { AX prior to } \\
\text { FESS }\end{array}$ & $\begin{array}{c}\text { Mean PA IgG six } \\
\text { months prior to } \\
\text { FESS }\end{array}$ & $\begin{array}{l}\text { Mean ex- } \\
\text { pected FEV1 six } \\
\text { months prior } \\
\text { FESS }\end{array}$ & $\begin{array}{l}\text { Lower airway } \\
\text { samples with } \\
\text { PA or AX one } \\
\text { year prior to } \\
\text { FESS }\end{array}$ & $\begin{array}{c}\text { Lower airway } \\
\text { samples with } \\
\text { PA or AX one } \\
\text { year prior to } \\
\text { FESS }\end{array}$ \\
\hline 11-year-old girl & PA & PA & 0 & 1.15 & $97 \%$ & $62 \%$ & 523 days \\
\hline 16-year-old boy & PA & PA & 2 & 2.64 & $94 \%$ & $60 \%$ & 593 days \\
\hline $\begin{array}{l}\text { 22-year-old } \\
\text { man. LTX }\end{array}$ & $A X$ & $A X$ & 4 & - & $57 \%$ & $77 \%$ & $\begin{array}{l}\text { Still no } \\
\text { regrowth after } \\
982 \text { days }\end{array}$ \\
\hline $\begin{array}{l}\text { 31-year-old } \\
\text { woman. LTX }\end{array}$ & PA & PA & 4 & 5.75 & $60 \%$ & $75 \%$ & 508 days \\
\hline
\end{tabular}

mined that only approval of the additionally BAL was needed. The study was approved by the local ethics committee (H-A2008-141). All patients gave informed consent, for patients $<18$ years of age, consent was also obtained from their parents.

\section{Statistical analysis}

SAS 9.1.3 was used for statistical analyses. The data were continuous and in all cases the differences between the pre- and postoperative data had an approximately normal distribution. The data fulfilled the criteria for normality and equal variance. $A$ two-sample paired t-test or an ANOVA test was used to compare the pre- and postoperative data.

When comparing the change in lung infection status, the nominal data were analysed by McNemar's test (two categories were merged). 


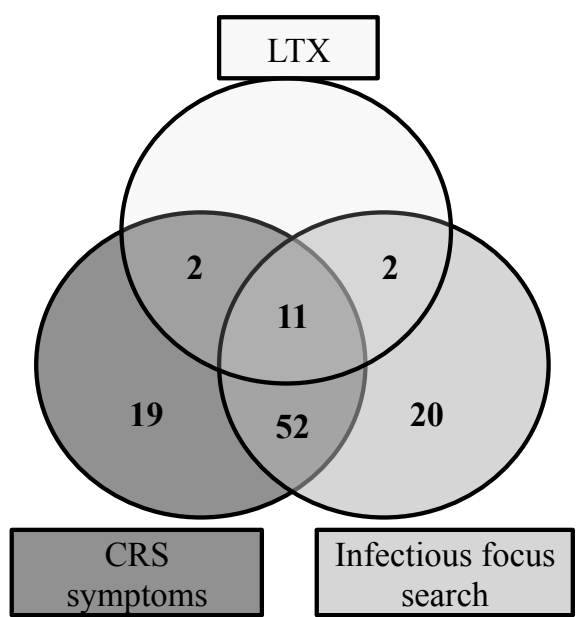

Figure 2.The criteria fulfilled for FESS in 106 CF patients undergoing surgery. (CRS: chronic rhinosinusitis (1); LTX: lung transplantation).

\section{Results}

\section{Study population characteristics}

Demographic data on the 106 included patients are shown in Table 1 and their criteria for FESS appear in Figure 2; in the study period, 21 patients had surgery twice and 4 had surgery three times; 4 patients had revision surgery during the first postoperative year because of a satisfactory but transient effect of the primary surgery.

The average time between LTX and FESS was 3.5 years $(1 / 2-11$ years). None of the patients had LTX during the year after FESS.

Upper airway culture results
All but one patient had bacterial growth from at least one sinus in their perioperatively obtained samples, but only 8 patients showed fungus isolates (Aspergillus, Candida species, and unidentified yeast). In 71 patients (67\%) the same type of CF pathogen was perioperatively cultured from the sinuses and in the lungs the previous year. In 35 patients (33\%) there was no correlation between lung and sinus bacteriology; these also included one $(\mathrm{CF}+(\mathrm{i}))$ patient with $A$. xylosoxidans in the sinuses but $P$. aeruginosa in the lungs, one $(\mathrm{CF}+(\mathrm{c}))$ patient without $\mathrm{CF}$ pathogens in the sinuses, and 4 (CF-) patients ( 2 LTX) where $P$. aeruginosa was found only in the sinuses.

\section{Lower airway culture results}

The one-year prevalence of CF+(i) patients decreased by $38 \%$ (Cl: $24 \%-51 \%$ ) after FESS (58\% at surgery compared with $36 \%$ one year postoperatively; $\mathrm{p}<0.01)$. The one-year prevalence of (CF-) patients increased by $150 \%$ (Cl: $71 \%-310 \%$ ) after FESS (15\% at surgery compared with $38 \%$ one year postoperatively; $p$ $<0.01$ ) (Table 2).

The frequency of pre- and postoperative lower airway cultures with pathogenic growth is illustrated in Figure 3 and shows a significant decrease in occurrence of CF pathogens in the postoperative samples. In subgroup analyses, the significant reduction of positive lower respiratory cultures was seen in the (CF+(i)) patients with simultaneous growth of CF pathogens in their sinuses and lungs ( $27 \%$ vs. $16 \% ; \mathrm{p}<0.01)$, and in $(C F+(\mathrm{c}))$ patients $(87 \%$ vs. $76 \% ; p<0.05)$; the latter mainly due to four successful cases shown in Table 3. There was a high correlation between the number of positive lower airway cultures and the number of days from a positive culture to the next negative

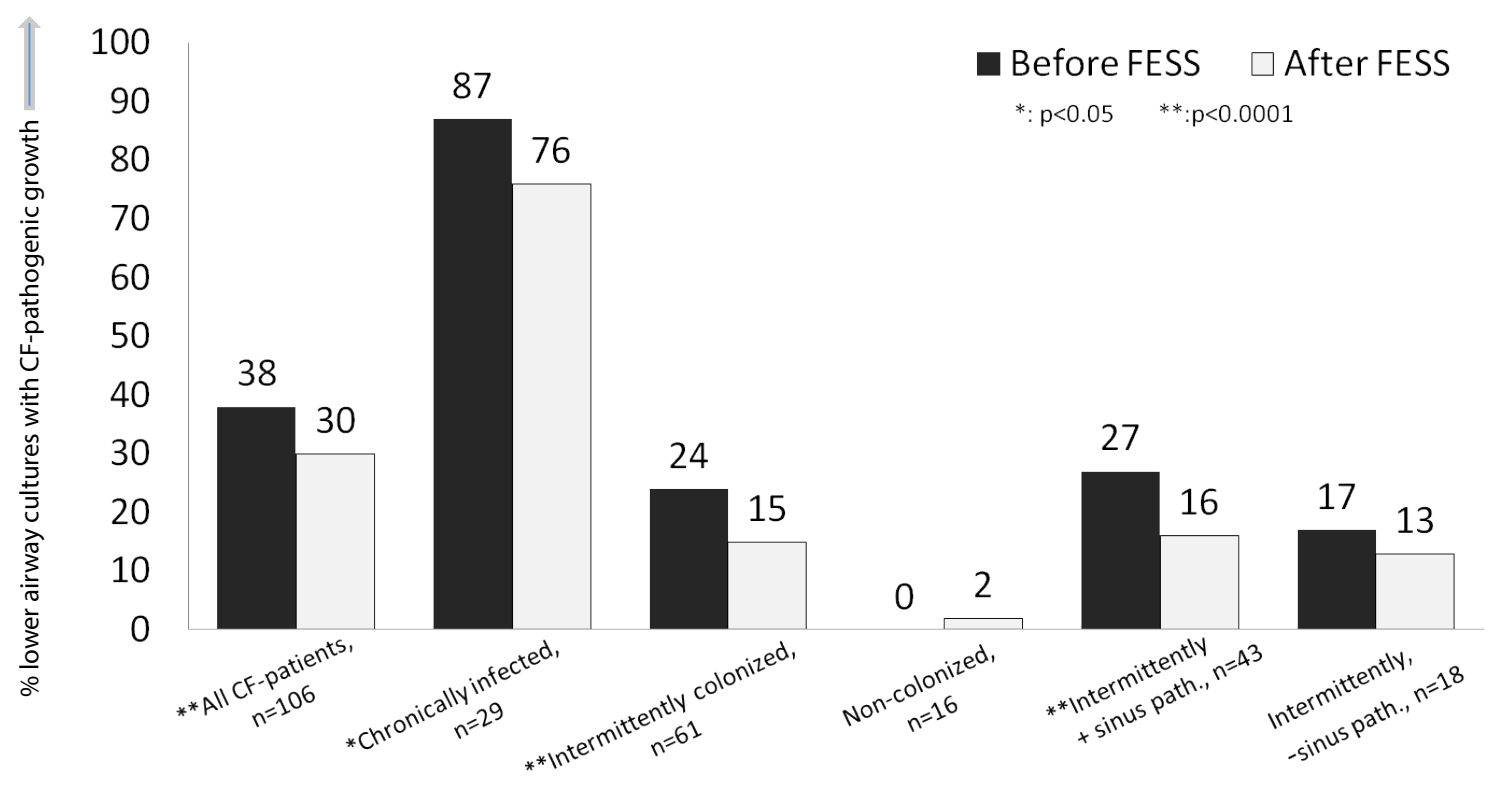

Figure 3. Frequencies of lower airway cultures with growth of CF-pathogenic Gram-negative bacteria a year before and after FESS, distributed on lung infection status and on the perioperatively bacterial findings in the sinuses. 
Table 4. Pre- and post-FESS obtained clinical data from the 106 included CF patients divided by their grade of pulmonary infection.

\begin{tabular}{|c|c|c|c|c|}
\hline & Non-infected & $\begin{array}{l}\text { Intermittently } \\
\text { colonized }\end{array}$ & $\begin{array}{l}\text { Chronically } \\
\text { infected }\end{array}$ & Total \\
\hline $\begin{array}{l}\text { \%-pathogenic sinus bacteria (P. aeruginosa, } A \text {. xylosoxidans } \\
\text { or B. cepacis complex) }\end{array}$ & $25 \%$ & $72 \%$ & $95 \%$ & $72 \%$ \\
\hline $\begin{array}{l}\text { Mean no. of lower airway cultures one year prior / one year } \\
\text { after FESS }\end{array}$ & $\begin{array}{l}10.4(2-15) \\
10.4(2-15)\end{array}$ & $\begin{array}{l}13.5(8-22) \\
11.2(3-24)\end{array}$ & $\begin{array}{l}14.1(2-35) \\
12.3(1-42)\end{array}$ & $\begin{array}{l}13.2 \\
11.4\end{array}$ \\
\hline $\begin{array}{l}\text { Mean no. of lung function tests and z-BMI one year before } \\
\text { / one year after FESS }\end{array}$ & $\begin{array}{l}9(0-15) \\
8(1-13)\end{array}$ & $\begin{array}{l}13(1-30) \\
11(1-20)\end{array}$ & $\begin{array}{l}10(1-18) \\
10(0-18)\end{array}$ & $\begin{array}{l}12 \\
10\end{array}$ \\
\hline $\begin{array}{l}\text { Mean FEV1 12/6 months before and } 6 / 12 \text { months after } \\
\text { FESS (\%) }\end{array}$ & $\begin{array}{l}82 / 80 \\
79 / 79\end{array}$ & $\begin{array}{l}85 / 86 \\
86 / 84\end{array}$ & $\begin{array}{l}72 / 72 \\
70 / 68\end{array}$ & $\begin{array}{l}81 / 81 \\
81 / 79^{*}\end{array}$ \\
\hline $\begin{array}{l}\text { Mean FEV1 slope (\%) 12/6 months before and 6/12 months } \\
\text { after FESS }\end{array}$ & $\begin{array}{l}-4.33 /-1.48 \\
12.71 /-0.89\end{array}$ & $\begin{array}{l}-0.67 / 1.44 \\
2.38 /-1.41\end{array}$ & $\begin{array}{l}0.57 / 5.63 \\
-8.88 /-1.33\end{array}$ & $\begin{array}{l}-0.85 / 1.15 \\
0.27 /-1.33\end{array}$ \\
\hline $\begin{array}{l}\text { Mean FVC } 12 / 6 \text { months before and } 6 / 12 \text { months after FESS } \\
\text { (\%) }\end{array}$ & $\begin{array}{l}93 / 91 \\
91 / 91\end{array}$ & $\begin{array}{l}95 / 95 \\
96 / 94\end{array}$ & $\begin{array}{l}85 / 85 \\
84 / 83\end{array}$ & $\begin{array}{l}92 / 92 \\
92 / 91^{*}\end{array}$ \\
\hline $\begin{array}{l}\text { Mean FVC slope (\%) 12/6 months before and 6/12 months } \\
\text { after FESS }\end{array}$ & $\begin{array}{r}-4.05 /-2.90 \\
10.80 / 1.74\end{array}$ & $\begin{array}{l}-1.16 / 0.22 \\
-0.47 /-1.04\end{array}$ & $\begin{array}{l}0.62 / 6.37 \\
-6.77 / 0.33\end{array}$ & $\begin{array}{l}-1.11 / 1.27 \\
-0.71 /-0.52\end{array}$ \\
\hline $\begin{array}{l}\text { Mean z-BMI 12/6 months before and 6/12 months after } \\
\text { FESS }\end{array}$ & $\begin{array}{l}-0.67 /-0.64 \\
-0.65 /-0.72\end{array}$ & $\begin{array}{l}-0.05 /-0.01 \\
-0.04 /-0.17\end{array}$ & $\begin{array}{l}-0.45 /-0.62 \\
-0.46 /-0.49\end{array}$ & $\begin{array}{l}-0.25 /-0.27 \\
-0.25 /-0.34\end{array}$ \\
\hline $\begin{array}{l}\text { Mean IgG } 12 / 6 \text { months before and } 6 / 12 \text { months after FESS } \\
\text { (No. of patients) }\end{array}$ & $\begin{array}{l}2.1 / 1.8 \\
2.0 / 2.0 \\
(10)\end{array}$ & $\begin{array}{l}3.4 / 3.7 \\
2.7 / 2.7 \\
(54)\end{array}$ & & $\begin{array}{l}3.1 / 3.6 \\
2.6 * / 2.6 \\
(64)\end{array}$ \\
\hline
\end{tabular}

$*: p<0.05$

Table 5. Results of the questionnaires before and after FESS.

\section{Pre-operatively Three months Six months Twelve months}

Patients who completed SNOT-22, (response rate), [mean time after FESS]

Mean SNOT-22

Patients who completed CFQ-R, (response rate), [mean time after FESS]

Mean (CFQ-R)

6-13 years:

More than 13 years:

Total:

86

20

67
79 (92\%)

[103 days]
64 (80\%)

[367 days]

$14^{*}$

53 (79\%)

[168 days]

$42(69 \%)$

[369 days] culture $(r h o=0.93 ; p=0.01)$.

\section{Spirometry results}

A negligible, but nevertheless, significant decrease was seen in FVC and FEV1 the year after FESS (Table 4).

\section{Body mass index results}

No significant changes were seen in the BMI z-scores (Table 4).
Specific serum antibody levels

Specific anti-Pseudomonas IgG antibodies decreased significantly during the first 6 postoperative months; however, the decrease was non-significant within 12 months after FESS (Table 4).

\section{SNOT-22 results}

A decrease was seen in sinonasal symptoms 3 and 12 months after FESS $(p<0.01$ ) (Table 5). As expected, cough, waking up 
tired, and fatigue were highly rated as important items that affected the health, but nasal blockage, facial pressure and sense of smell/taste were also highly rated and improved after 3 months ( $p<0.01$ ). After 12 months an improvement could still be detected in nasal blockage and facial pressure $(p<0.01)$.

\section{Health-related quality of life (HRQOL) results}

An increase in HRQOL was seen 6 months postoperatively $(p<$ $0.05)$. However, at 12 months postoperatively no significant differences in HRQOL were observed (Table 5).

\section{Surgical complications}

No perioperative major blood loss was observed but one patient had an accidental penetration of the orbital lamina (with unaffected vision). One patient was hospitalized three days after surgery because of epistaxis, one patient experienced transient paresthesia of the skin below the eye and discomfort when looking to the side (the orbit was not entered during surgery), and one patient had epiphora requiring intervention. Apart from one patient who experienced decreased sense of smell (surgically unexplained), no persistent sequelae were noted.

\section{Discussion}

In this prospective cohort study, we present data from a large cohort of CF patients undergoing FESS and adjuvant therapy. A significant reduction in the frequency of lower airway cultures with CF-pathogens accomplished after FESS is shown for the first time. Subsequently, the proportion of intermittently colonised $(\mathrm{CF}+(\mathrm{i}))$ patients decreased as a consequence of the increased number of non-infected (CF-) patients. Specific lgG against $P$. aeruginosa decreased and quality of life including sinonasal symptoms was improved. Only a small decrease in lung function was seen after a year, which is in agreement with an annual average decline of $1-2 \%$ in CF patients ${ }^{(22)}$.

Other studies have addressed the effect of sinus surgery on CF lungs using varying parameters and showing inconsistent results ${ }^{(23)}$. Comparable to our study, one prospective study performed extensive sinus surgery intending to eradicate sinus bacteria in a group of 82 LTX patients ${ }^{(10)}$, showing that $P$. aeruginos $a$ and $B$. cepacia complex could be eradicated from the sinuses, resulting in reduced lung allograft infections. Shatz ${ }^{(24)}$ found decreased antibiotic use, a lower hospitalisation rate, and an increase in FEV1 six months after FESS among 15 non-LTX patients. Lewiston et al. ${ }^{(25)}$ postoperatively installed tobramycin in the sinuses and reported a lower rate of $P$. aeruginosa in the lungs of 11 LTX patients. Other studies differ in several ways: as they were retrospective, most did less extensive surgery compared with our procedures, none focused on the grading of pulmonary infection and only few included intensive follow-up with use of nasally applied antibiotics. These studies found no postoperative reduction in lung colonisation; however, some found a slight improvement of lung function, lower hospitalisation rates, and reduced use of antibiotics ${ }^{(26-34)}$.

In the present study, $(\mathrm{CF}+(\mathrm{i}))$ patients simultaneously sinus and pulmonary colonised experienced the greatest benefit from our treatment protocol; it is likely that the treatment protected the lungs in this group of 'risk' patients from subsequent recurrent lung colonisation and chronic infection. The challenge is to detect these specific patients and to estimate when they may benefit from FESS. Our results support previously published studies showing a that LTX patients benefits from FESS ${ }^{(25,35)}$, and further indicate that patients at the early stage of chronic lung infection with well-preserved lung function and low levels of specific antibodies, such as the patients in Table 3, may benefit from FESS. We put forward the possibility that these patients may be false positively categorized as $(\mathrm{CF}+(\mathrm{c}))$ since lower airway samples can be cross-contaminated by secretions from the upper airways; in these cases the antibody response has shown to be helpful in distinguishing $(\mathrm{CF}+(\mathrm{i}))$ patients from $(\mathrm{CF}+(\mathrm{c}))$ (12,19).

The SNOT-22 questionnaire is suitable as a disease-specific instrument in sinonasal research and is widely used in non CF patients ${ }^{(20)}$. We found that the questionnaire is a good tool for evaluating CRS symptoms; however, the risk of CF patients underreporting symptoms of CRS should be taken into account ${ }^{(36)}$. The majority of patients reported decreased nasal discharge and decreased nasal blockage after FESS despite very low preoperative scoring of these two items.

The CFQ-R has undergone validity testing ${ }^{(37)}$ and is a widely used HRQOL measure for CF. CRS affects quality of life ${ }^{(38)}$ but the CFQ-R contains only one question on CRS. Nevertheless, in our population, CFQ-R improved six months after FESS.

All our results, both positive and negative, highlight the need for guidelines for when to offer CF patients sinus surgery and/or nasal care.

Although we did not address the need for revision surgery, our prospective study gives weight to the conclusions of the recently published European position paper on rhinosinusitis and fulfils the requirements for new studies (1): "Future prospective studies are needed to further elucidate the role of medical and surgical therapy in CF patients with chronic rhinosinusitis (CRS), but the data on surgical therapy support the safety and efficacy of endoscopic sinus surgery".

The strengths of our study are the large cohort, its prospective design taking multiple parameters into consideration, the relatively extensive surgery done to eradicate CF pathogens, and, 
in particular, the unchanged CF treatment protocol throughout the intervention ${ }^{(13)}$. Longer follow-up times and larger cohorts with the possibility of randomising patients into different treatment groups are needed to further elucidate the role of medical and surgical therapy among CF patients. With this study design, the effect of FESS on pulmonary infections could not be sufficiently evaluated in (CF-) patients who had CF pathogens only in the sinuses and not in the lungs.

Our study is limited by the lack of a control group and the tardy initiation of the questionnaires. Further, we were initially reluctant to explore all sinuses. Nevertheless, the aim for each FESS procedure was to explore all sinuses creating megaantrostomies, now also recommended in the recently published guidelines ${ }^{(1)}$. Apart from nasal irrigations with saline in CF sinuses, there is low level evidence to support our postoperative adjuvant therapy ${ }^{(1)}$. The use of topical steroids, additional dornase-alfa (1), and choice of antibiotic drug(s) may be considered in the future.

\section{Conclusion}

In conclusion, sinus surgery combined with postoperative antibiotic treatment significantly reduced the frequency of pulmonary samples positive for CF pathogens during the first postoperative year. Our results support FESS with adjuvant therapy, especially in intermittently colonised CF patients; however, guidelines are warranted for criteria for FESS based on clinical and paraclinical parameters.

\section{Acknowledgement}

We thank Ketty Vinding and Majbritt Presfeldt at the CF Centre Copenhagen, and the Pseudomonas laboratory technicians at the Department of Clinical Microbiology (Katja Bloksted, Ulla Johansen, Lene Nørregaard, Helle Nordbjerg, Pia Poss, Vibeke Clausen, Camilla Thranow, Sarah Buur) for their dedication to this project. Professor Torben Martinussen is thanked for statistical advice.

Schering-Plough A/S financed the SNOT-22 translation. Kasper Aanaes was financially supported by The Candys Foundation, a non-profit organization. Helle Krogh Johansen was supported by a clinical research stipend from the Novo Nordic Foundation

\section{Authorship contribution}

All authors contributed equally in the design of the study, interpreting the results and adjusting the manuscript. In close dialog with the other authors KA included the patients, made the statistic analyses and wrote the manuscript. KA and CvB did the surgical procedures. $\mathrm{HKJ}$ and $\mathrm{NH}$ analysed and collected the paraclinical data. MS, FFB, TP and KGN collected the lung function, $\mathrm{BMI}$ and demographic data.

\section{Conflict of interest}

None to declare.

\section{References}

1. Fokkens WJ, Lund VJ, Mullol J, Bachert C, Alobid I, Baroody F, et al. EPOS 2012: European position paper on rhinosinusitis and nasal polyps 2012. A summary for otorhinolaryngologists. Rhinology. 2012; 50: 1-12.

2. Hansen SK, Rau MH, Johansen HK, Ciofu O, Jelsbak L, Yang L, et al. Evolution and diversification of Pseudomonas aeruginosa in the paranasal sinuses of cystic fibrosis children have implications for chronic lung infection. ISME J. 2012; 6: 31-45.

3. Johansen HK, Aanaes K, Pressler T, Nielsen KG, Fisker J, Skov M, et al. Colonisation and infection of the paranasal sinuses in cystic fibrosis patients is accompanied by a reduced PMN response. J Cyst Fibros. 2012; 11: 525-531.

4. Aanaes K, Rickelt LF, Johansen HK, von BC, Pressler T, Hoiby N, et al. Decreased mucosal oxygen tension in the maxillary sinuses in patients with cystic fibrosis. J Cyst Fibros. 2011; 10: 114-120.

5. Kolpen M, Hansen CR, Bjarnsholt $T$ Moser C, Christensen LD, van GM, et al. Polymorphonuclear leucocytes consume oxygen in sputum from chronic Pseudomonas aeruginosa pneumonia in cystic fibrosis. Thorax. 2010; 65: 57-62.

6. Aanaes K, Johansen HK, Poulsen SS, Pressler T, Buchwald C, Hoiby N. Secretory IgA as a diagnostic tool for Pseudomonas aeruginosa respiratory colonization. J Cyst Fibros. 2013; 12: 81-87

7. Mainz JG, Naehrlich L, Schien M, Kading M Schiller I, Mayr S, et al. Concordant genotype of upper and lower airways $P$ aeruginosa and $\mathrm{S}$ aureus isolates in cystic fibrosis. Thorax. 2009; 64: 535-540.

8. Nunley DR, Grgurich W, lacono AT, Yousem S, Ohori NP, Keenan RJ, et al. Allograft colonization and infections with pseudomonas in cystic fibrosis lung transplant recipients. Chest. 1998; 113: 1235-1243.

9. Aanaes K, von BC, Hjuler T, Skov M, Alanin $M$, Johansen HK. The effect of sinus surgery with intensive follow-up on pathogenic sinus bacteria in patients with cystic fibrosis. Am J Rhinol Allergy. 2013; 27: 1-4.

10. Vital D, Hofer M, Benden C, Holzmann D, Boehler A. Impact of Sinus Surgery on Pseudomonal Airway Colonization, Bronchiolitis Obliterans Syndrome and Survival in Cystic Fibrosis Lung Transplant Recipients. Respiration. 2012 Aug 22.

11. Khalil HS, Nunez DA. Functional endoscopic sinus surgery for chronic rhinosinusitis.
Cochrane Database Syst Rev. 2006; (3): CD004458.

12. Johansen HK, Norregaard L, Gotzsche PC, Pressler T, Koch C, Hoiby N. Antibody response to Pseudomonas aeruginosa in cystic fibrosis patients: a marker of therapeutic success?--A 30-year cohort study of survival in Danish CF patients after onset of chronic $P$. aeruginosa lung infection. Pediatr Pulmonol. 2004; 37: 427-432.

13. Koch C, Hoiby N. Diagnosis and treatment of cystic fibrosis. Respiration. 2000; 67: 239247.

14. Lee TW, Brownlee KG, Conway SP, Denton M, Littlewood JM. Evaluation of a new definition for chronic Pseudomonas aeruginosa infection in cystic fibrosis patients. J Cyst Fibros. 2003: 2: 29-34.

15. Høiby N, Frederiksen B. Microbiology of cystic fibrosis. In: Hodson ME GD, editor. Cystic Fibrosis. 2nd edition ed. Arnold; 2000. p. 83-107.

16. Hankinson JL, Odencrantz JR, Fedan KB. Spirometric reference values from a sample of the general U.S. population. Am J Respir Crit Care Med. 1999; 159: 179-187.

17. Wang $X$, Dockery DW, Wypij D, Fay ME, Ferris BG, Jr. Pulmonary function between 6 and 18 years of age. Pediatr Pulmonol. 1993; 
15: $75-88$

18. Nysom K, Molgaard C, Hutchings B Michaelsen KF. Body mass index of 0 to 45-y-old Danes: reference values and comparison with published European reference values. Int J Obes Relat Metab Disord. 2001; 25: 177-184.

19. Pressler T, Frederiksen B, Skov M, Garred P, Koch C, Hoiby N. Early rise of anti-pseudomonas antibodies and a mucoid phenotype of pseudomonas aeruginosa are risk factors for development of chronic lung infection--a case control study. J Cyst Fibros. 2006; 5: 9-15.

20. Hopkins C, Gillett S, Slack R, Lund VJ, Browne JP. Psychometric validity of the 22-item Sinonasal Outcome Test. Clin Otolaryngol. 2009; 34: 447-454.

21. Quittner AL, Buu A, Messer MA, Modi AC, Watrous M. Development and validation of The Cystic Fibrosis Questionnaire in the United States: a health-related quality-of-life measure for cystic fibrosis. Chest. $2005 ; 128$ : 2347-2354

22. Taylor-Robinson D, Whitehead M Diderichsen F, Olesen HV, Pressler T, Smyth $\mathrm{RL}$, et al. Understanding the natural progression in \%FEV1 decline in patients with cystic fibrosis: a longitudinal study. Thorax. 2012; 67: 860-866.

23. Macdonald Kl, Gipsman A, Magit A, Fandino M, Massoud E, Witterick IJ, et al. Endoscopic sinus surgery in patients with cystic fibrosis: A systematic review and meta-analysis of pulmonary function. Rhinology. 2012; 50: 360-369.

24. Shatz A. Management of recurrent sinus disease in children with cystic fibrosis: a combined approach. Otolaryngol Head Neck Surg. 2006; 135: 248-252.
25. Lewiston N, King V, Umetsu D, Starnes $V$, Marshall S, Kramer M, et al. Cystic fibrosis patients who have undergone heart-lung transplantation benefit from maxillary sinus antrostomy and repeated sinus lavage. Transplant Proc. 1991; 23: 1207-1208.

26. Jarrett WA, Militsakh O, Anstad M Manaligod J. Endoscopic sinus surgery in cystic fibrosis: effects on pulmonary function and ideal body weight. Ear Nose Throat J. 2004; 83: 118-121

27. Kempainen RR, Sajan JA, Pylkas AM, Dunitz JM, Rimell FL, Milla CE. Effect of Endoscopic Sinus Surgery on Pulmonary Status of Adults with Cystic Fibrosis. Otolaryngol Head Neck Surg. 2012; 147: 557-562.

28. Leung MK, Rachakonda L, Weill D, Hwang $\mathrm{PH}$. Effects of sinus surgery on lung transplantation outcomes in cystic fibrosis. Am J Rhinol. 2008; 22: 192-196.

29. Madonna D, Isaacson G, Rosenfeld RM, Panitch $\mathrm{H}$. Effect of sinus surgery on pulmonary function in patients with cystic fibrosis. Laryngoscope. 1997; 107: 328-331.

30. Osborn AJ, Leung $R$, Ratjen $F$, James $A L$. Effect of endoscopic sinus surgery on pulmonary function and microbial pathogens in a pediatric population with cystic fibrosis. Arch Otolaryngol Head Neck Surg. 2011; 137: 542-547

31. Rosbe KW, Jones DT, Rahbar R, Lahiri T, Auerbach AD. Endoscopic sinus surgery in cystic fibrosis: do patients benefit from surgery? Int J Pediatr Otorhinolaryngol. 2001; 61: 113-119.

32. Triglia JM, Nicollas R. Nasal and sinus polyposis in children. Laryngoscope. 1997; 107: 963-966.

33. Kovell LC, Wang J, Ishman SL, Zeitlin PL, Boss EF. Cystic fibrosis and sinusitis in chil- dren: outcomes and socioeconomic status. Otolaryngol Head Neck Surg. 2011; 145: 146-153.

34. Roby BB, McNamara J, Finkelstein M Sidman J. Sinus surgery in cystic fibrosis patients: comparison of sinus and lower airway cultures. Int J Pediatr Otorhinolaryngol. 2008; 72: 1365-1369.

35. Holzmann D, Speich R, Kaufmann T, Laube I, Russi EW, Simmen D, et al. Effects of sinus surgery in patients with cystic fibrosis after lung transplantation: a 10-year experience. Transplantation. 2004; 77: 134-136.

36. Mainz JG, Koitschev A. Management of chronic rhinosinusitis in CF. J Cyst Fibros. 2009; 8 Suppl 1: S10-S14.

37. Bregnballe $V$, Thastum M, Lund LD, Hansen $C R$, Preissler T, Schiotz PO. Validation of the Danish version of the revised cystic fibrosis quality of life questionnaire in adolescents and adults (CFQ-R14+). J Cyst Fibros. 2008; 7: 531-536.

38. Sahlstrand-Johnson P, Ohlsson B, Von Buchwald C, Jannert M. A multi-centre study on quality of life and absenteeism in patients with CRS referred for endoscopic surgery. Rhinology. 2011; 49: 420-428.

Kasper Aanaes

Department of Otolaryngology

Head \& Neck Surgery and Audiology

Rigshospitalet

Blegdamsvej 9

DK-2100 Copenhagen

Denmark 